\title{
Comment on: Transforming ophthalmic education into virtual learning during COVID-19 pandemic: a global perspective
}

\author{
Nikolaos Tzoumas ${ }^{1,2} \cdot$ Toby Boote $^{1} \cdot$ Jennie Higgs ${ }^{1} \cdot$ Heather Ellis $^{1} \cdot$ Baljean Dhillon ${ }^{1}{ }^{1} \cdot$ Peter Cackett $^{1}$
}

Received: 9 August 2020 / Revised: 3 September 2020 / Accepted: 4 September 2020 / Published online: 14 September 2020

(c) The Royal College of Ophthalmologists 2020

\section{To the Editor:}

We read with interest the paper by Chatziralli et al. which highlights the unique opportunities COVID-19 provides to embrace technologically driven teaching modalities in ophthalmic education [1]. We designed and implemented an e-learning tool to reduce extraneous cognitive overload in undergraduate ophthalmic teaching and would like to share our experience with readers.

Beyond its evolving impact on postgraduate training, COVID-19 threatens undergraduate ophthalmic teaching, exposure to which is increasingly limited [2]. Cognitive load theory (CLT) is a well-established model of information processing, which assumes a limited working memory, whereby the reduction of superfluous knowledge improves retention [3]. Adherence to CLT principles in resource design may improve student satisfaction.

We applied over a decade of course evaluations $(n=$ 1109) to the design of an e-learning resource tailored to reduce extraneous cognitive load, and further studied its uptake amongst senior Edinburgh Medical School undergraduates through a non-randomised pretest/posttest study ( $n=116$ responses, 29\% attrition) over an 8-week assessment period. Eight goal-free ophthalmic disease-specific factsheets were created, integrating basic and clinical sciences teaching across $30+$ information sources (Fig. 1).
Other strategies employed included coherence (exclusion of extraneous words), spatiotemporal contiguity (presenting corresponding words and pictures in close proximity and simultaneously), signalling (highlighting important words), and personalisation (employing a conversational style) [4]. Key facts were thematically arranged in comparative statements underscoring variations between differential diagnoses, and hyperlinked to online content.

Module satisfaction correlated with teaching quality $\left(r^{2}=0.61, \quad P<0.01\right), \quad$ resource availability $\left(r^{2}=0.62\right.$, $P<0.01)$, and learning objective achievement $\left(r^{2}=0.64\right.$, $P<0.01)$. Compared to existing resources, the intervention received improved ratings for quality (36 percentage points increase, $P<0.001,95 \%$ CI $28-45$ ), utility (27 percentage points, $P<0.001,95 \%$ CI 15-39), reliability (34 percentage points, $P<0.001,95 \%$ CI 23-46), and satisfaction (44 percentage points, $P<0.001,95 \%$ CI 34-53) (Fig. 2). All comparative responses were more favourable, and all associated descriptors were positive (144\% increase).

Our resources conferred rapid improvements in the perceived quality, utility, and reliability of, and overall satisfaction with, local ophthalmology teaching materials. We, therefore, support the authors' conclusion that high-quality content remains an educational priority [1]. Face-to-face teaching restrictions post COVID-19 will require innovative and accessible learning materials [5].
Nikolaos Tzoumas

nik.tzoumas@ncl.ac.uk

1 Ophthalmology, Division of Health Sciences, The University of Edinburgh, Edinburgh, UK

2 Biosciences Institute, Newcastle University, Newcastle upon Tyne, UK 
Fig. 1 An example resource design for teaching glaucoma, integrating various sources of information to communicate essential clinical information effectively through use of visual information. Clinical image courtesy of Jonathan Trobe, M.D., accessed at https:// commons.wikimedia.org/wiki/ File:Acute_Angle_Closure-gla ucoma.jpg, no changes made (CC BY 3.0).

\section{Glaucoma}

What is glaucoma? Glaucoma is a progressive optic neuropathy. It is a final common pathway for a number of conditions, for most of which raised intraocular pressure (IOP) is the chief risk factor. It is the second leading cause of blindness worldwide.
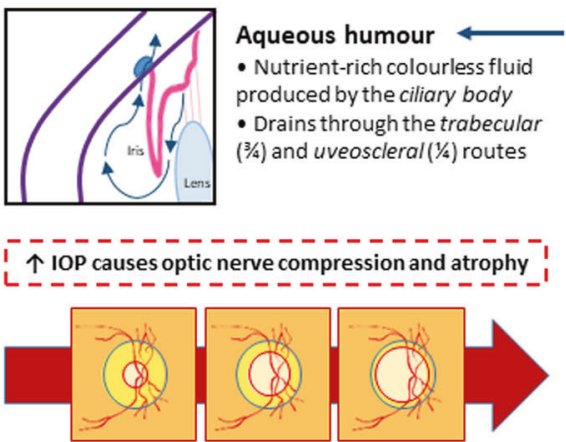

Large Cup:Disc ratio in glaucoma

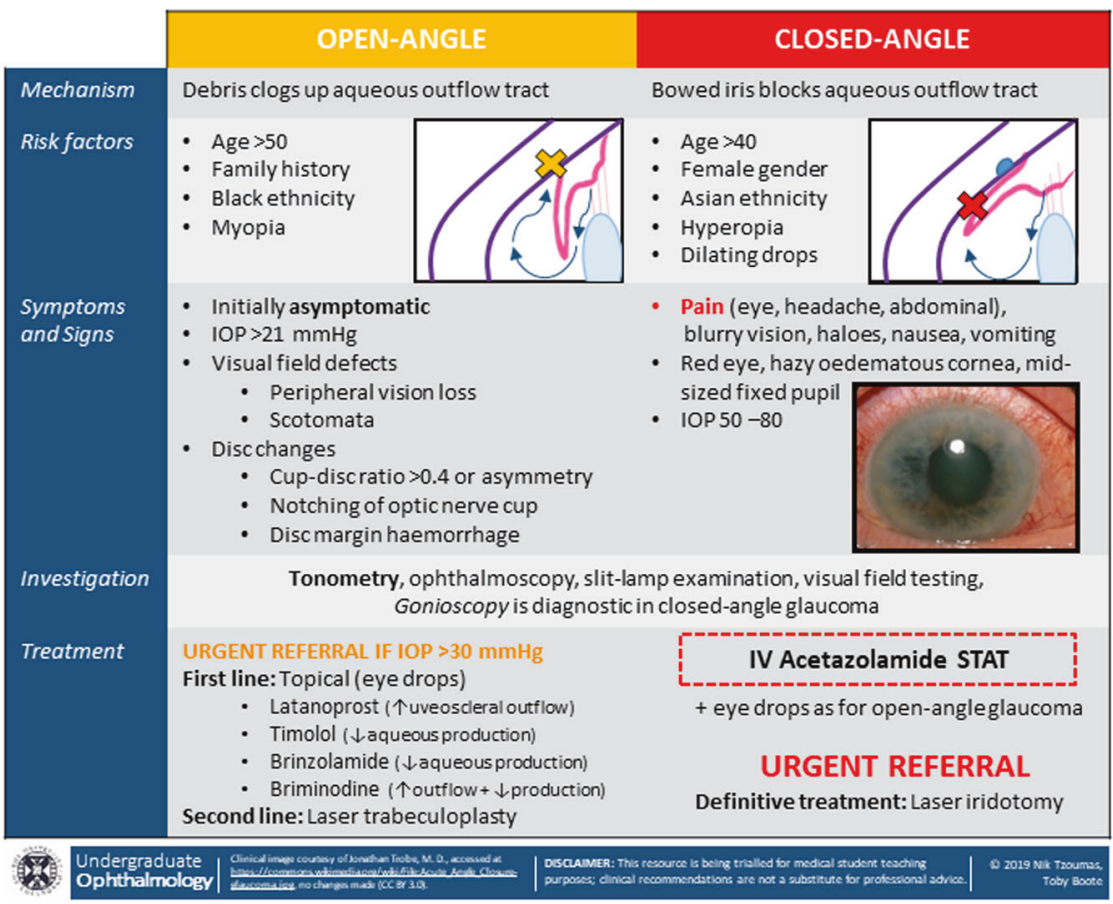

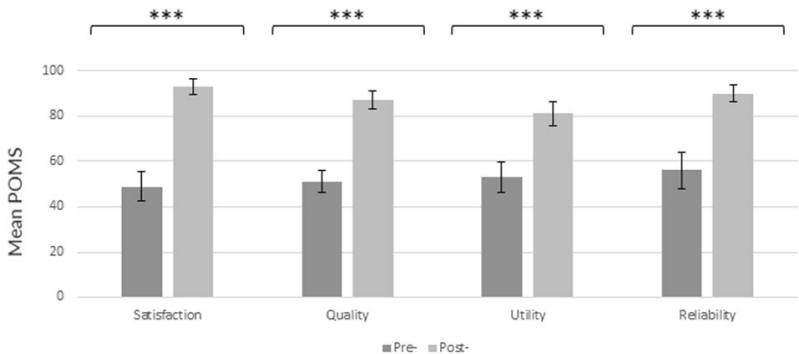

Fig. 2 Pretest and posttest comparison of mean percent of maximum possible scores (POMS) achieved in each key domain. Error bars signify confidence intervals. POMS $=[($ observed - minimum $) /$ (maximum - minimum)].

\section{Compliance with ethical standards}

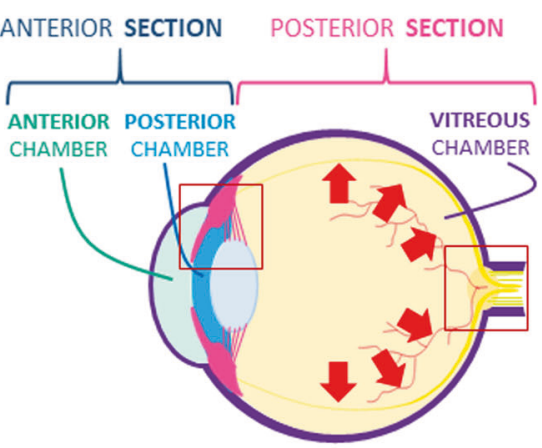

CLOSED-ANGLE

Conflict of interest The authors declare that they have no conflict of interest.

Publisher's note Springer Nature remains neutral with regard to jurisdictional claims in published maps and institutional affiliations.

\section{References}

1. Chatziralli I, Ventura CV, Touhami S, Reynolds R, Nassisi M, Weinberg $\mathrm{T}$, et al. Transforming ophthalmic education into virtual learning during COVID-19 pandemic: a global perspective. Eye. 2020:1-8. https://doi.org/10.1038/s41433-020-1080-0. [Epub ahead of print] 
2. Hill S, Dennick R, Amoaku W. Present and future of the undergraduate ophthalmology curriculum: a survey of UK medical schools. Int J Med Educ. 2017;8:389-95.

3. Van Merriënboer JJ, Sweller J. Cognitive load theory in health professional education: design principles and strategies. Med Educ. 2010;44:85-93.
4. Mayer RE. Multimedia learning. In: Psychology of learning and motivation. Academic Press; 2002. Vol 41, p. 85-139.

5. Dhillon N, Dhillon B. On-line lessons learned post Covid-19: mater artium necessitas [letter]. BMJ Stel. 2020. Available from: https://stel.bmj.com/content/6/4/196.responses. [Accessed 17 July 2020]. 